This is an electronic reprint of the original article. This reprint may differ from the original in pagination and typographic detail.

Author(s): Jääskelä, Päivikki; Häkkinen, Päivi; Rasku-Puttonen, Helena

Title: $\quad$ Supporting and constraining factors in the development of university teaching experienced by teachers

Year: $\quad 2017$

Version:

Please cite the original version:

Jääskelä, P., Häkkinen, P., \& Rasku-Puttonen, H. (2017). Supporting and constraining factors in the development of university teaching experienced by teachers. Teaching in Higher Education, 22(6), 655-671.

https://doi.org/10.1080/13562517.2016.1273206

All material supplied via JYX is protected by copyright and other intellectual property rights, and duplication or sale of all or part of any of the repository collections is not permitted, except that material may be duplicated by you for your research use or educational purposes in electronic or print form. You must obtain permission for any other use. Electronic or print copies may not be offered, whether for sale or otherwise to anyone who is not an authorised user. 
NOTICE: This is the author's version of a work that was accepted for publication in Teaching in Higher Education. Changes resulting from the publishing process, such as peer review, editing, corrections, page numbering, structural formatting, and other quality control mechanisms may not be reflected in this document. Changes may have been made to this work since it was submitted for publication. A definitive version was subsequently published online 15 Jan 2017 in Teaching in Higher Education, DOI: 10.1080/13562517.2016.1273206. Link to this article: http://dx.doi.org/10.1080/13562517.2016.127320626

To cite this article: Päivikki Jääskelä, Päivi Häkkinen \& Helena Rasku-Puttonen (2017):

Supporting and constraining factors in the development of university teaching experienced by teachers, Teaching in Higher Education, DOI: 10.1080/13562517.2016.1273206

Article title: Supporting and constraining factors in the development of university teaching experienced by teachers

Authors:

\section{Päivikki Jääskelä (corresponding author)}

University of Jyvaskyla, Department of Teacher Education, Jyvaskyla, Finland

Postal address: P.O. Box 35, FI-40014 University of Jyvaskyla, Finland

Phone number: +358 408053333

E-mail: paivikki.jaaskela@jyu.fi

\section{Päivi Häkkinen}

University of Jyvaskyla, Finnish Institute for Educational Research, University of Jyvaskyla, Finland

Postal address: P.O. Box 35, FI-40014 University of Jyvaskyla, Finland

Phone number: +358405843325

E-mail: paivi.m.hakkinen @jyu.fi

\section{Helena Rasku-Puttonen}

University of Jyvaskyla, Department of Teacher Education, Jyvaskyla, Finland

Postal address: P.O. Box 35, FI-40014 University of Jyvaskyla, Finland

Phone number: +358 503732119

E-mail: helena.rasku-puttonen@jyu.fi 


\title{
Supportive and constraining factors in the development of university teaching experienced by teachers
}

\begin{abstract}
Higher education calls for reform, but deeper knowledge about the prerequisites for teaching development and pedagogical change is missing. In this study, 51 university teachers' experiences of supportive or constraining factors in teaching development were investigated in the context of Finland's multidisciplinary network. The findings reveal that the supportive factors in teaching development arise from the nature of the development itself, i.e., from the teachers' opportunities to act as active agents in an authentic development process. Furthermore, the circumstances of the development also play essential roles (both constraining and supportive) in teaching development. Such support, at its best, will come when teachers and others view teaching development in the university context as being valuable and rewarding, and when teachers are encouraged by management and are supplemented with the necessary equipment, tools, and networks they need to do their job. Increasing interaction between the institutional levels can make educational development successful.
\end{abstract}

Keywords: teaching development, higher education, university teaching, structures of the development, academic work

\section{Introduction}

University teachers face pressures to renew their teaching practices and pilot new forms of learning that respond to the demands of working life and society. The utilisation of information and communication technologies (ICT) in teaching and learning is one example of the need for reform. Teachers from different disciplines have been challenged by both recent learning research and higher education policy to take an active and agentic role in the development of learning and teaching environments. In developing new kinds of learning environments, various underlying theoretical and pedagogical questions have been raised. Researchers call for pedagogically appropriate learning arrangements that are based on learner-centred learning, advocating the facilitation of students' autonomy, active agency, complex problem solving and collaborative knowledge construction so that deep learning can take place (Bransford et al. 2006). At the same time, education increasingly faces economic and managerial pressures. Such pressures are present in higher education policy, where there are calls for a more fluid graduation enhanced by flexible possibilities for studying that are independent of time and place and take place throughout the whole year. Global trends seem to demand greater efficacy, greater productivity and new systems of monitoring and evaluating, thus challenging the professional independence of teachers and educators (Adams 2000; Hökkä and Eteläpelto 2014).

Numerous studies targeted at course design and programme-level development have been conducted responding to the demands for educational renewal. These aim to model pedagogies and develop tools and practices to support higher education learning (Jääskelä and Nissilä 2015). Traditional teaching and learning methods, based on transmitting knowledge, have been reconsidered, often replaced by more active pedagogies (e.g., Glenn et al. 2012; Ramsden 2003; Roxå and Mårtensson 2008). The alternatives to traditional teaching practices include inquiry-based learning (Christopher et al. 2007), problem-based learning (Vanhanen et al. 2001) and peer instruction (Crouch and Mazur 2001). Furthermore, many ICT-supported teaching interventions have been conducted (Kirkwood and Price 2014). Teachers from different disciplines have also carried out individual pilot projects concerning 
learning environments and pedagogical approaches and tools; however, there has usually been a lack of research on the effectiveness of these approaches (Jääskelä and Nissilä 2015).

Despite the broad teaching development work that has been carried out, pedagogical development in higher education still appears inadequate in many ways. Teaching remains a 'fortress' of traditional pedagogy, including extensive 'one-to-many' lecturing, which is not a preferred method among the current pedagogical trends. The utilisation of new technologies to support learning and teaching varies greatly and has not been harnessed to serve pedagogically meaningful practices (Häkkinen and Hämäläinen 2012). Instead, it has been shown to concentrate on the means for replicating (or supplementing) existing teaching practices (Kirkwood and Price 2014). Teaching development in higher education focuses on the content that is produced by the current research in each discipline (Su 2011), but it does not typically support students' broader professional development (Jääskelä et al. 2016; Trede, Macklin, and Bridges 2012). Furthermore, the development of university teaching has traditionally been seen as an individual endeavour; good practices are not shared, and approaches are often reinvented due to a lack of support among colleagues (Stenfors-Hayes et al. 2011). It is therefore critical to ask what needs to be done for the development of teaching to trigger more visible change in educational practices and learning culture in different disciplines.

Various forms of interventions have concentrated on supporting individual teachers in their professional development. The functions and impacts of these interventions have been analysed. Formalised university teacher training and intensive teacher development programmes have become widespread models of support in many countries (Postareff, Lindblom-Ylänne, and Nevgi 2007; Trowler and Bamber 2005; Bamber 2008). Even though these training processes comprise differences in terms of their foci and implementation (Bamber et al. 2006; Gibbs and Coffey 2004), the ultimate purpose of these programmes is the improvement of (mainly new and inexperienced) teachers' pedagogical thinking and competence through conceptual change (Trigwell and Prosser 1996). Such a change is expected to promote teaching quality and student learning, leading to cultural change across the higher education system (Trowler and Bamber 2005; Bamber 2008). Other internationally used practices include short training courses (e.g., workshops and seminars) outside teachers' work contexts, work-related academic work groups, bilateral consulting, peer-assessment and mentoring, and student assessment of teaching (e.g., feedback) (Prebble et al. 2004).

Extensive training programmes that aim to develop professional competences have been found to be the most effective teacher development interventions in terms of changing teaching (Prebble et al. 2004; Ramsden 2003). These have been found to have a positive effect on transforming teachers' beliefs and their adoption of a more student-centred approach (Gibbs and Coffey 2004; Prebble et al. 2004; Stes, Coertjens, and Petegem 2010), as well as leading to teachers' increased self-efficacy (Postareff, Lindblom-Ylänne, and Nevgi 2007). However, the results do not demonstrate that the improvements stemming from university teacher training are directly linked to improved student learning (Trowler and Bamber 2005) or cultural change in departments (Fanghanel 2004). Furthermore, teacher development work has been criticised for its excessive individual focus (Warhurst 2008) or for surface learning that can only loosely be defined as academic development (Cox 2004; Prebble et al. 2004).

The widespread promotion of teaching and learning has been seen to require a strategic approach through the systematic development of enhancement cultures among faculty communities (Trowler and Bamber 2005). In many countries, where support for educational development is provided through institutional-level units, including the UK (Gosling 2001, 2009), Australia (Lee, Manathunga, and Kandlbinder 2010) and Sweden (Roxå and, Mårtensson 2008), there has been a movement in the core task of these units from 
providing training for individual teachers to being involved in organisational change processes, including the frameworks and infrastructure surrounding teaching within the institutions (Havnes and Stensaker 2006). According to Ramsden (2003), the development of university teaching should be carried out at multiple levels and in a variety of ways. On the one hand, we need individual, teacher-initiated innovations that encourage colleagues to try similar ideas. On the other hand, changes should also be made to the context of university teaching, including changes to academic leadership at different levels, policies on recognition and reward, and academic development programmes.

Several studies have paid attention to the role of scholarly communities in supporting and constraining teacher development and educational change. Lave and Wenger (1991) state that new teachers, in particular, can learn and develop educational practices if they experience legitimate peripheral participation in a community of practice. Moreover, it has been suggested that pedagogical practices should be developed more systematically through dialogic social learning activities among the whole academic staff (Warhurst 2006). However, the power structures of scholarly communities (Hodkinson 2005) and the individualistic character of academic work, including its valuing of autonomy and professional freedom (Warhurst 2008), have been found to constrain full participation and learning within the workplace. Teachers' professional learning in work communities has been described as a challenging interplay of social context and individual agency (Warhurst 2008, Eteläpelto et al. 2014). In aiming to cross the barriers to learning in the academic workplace, programmes constructed on the idea of faculty learning communities (Cox 2004) show promise for teaching development. By consciously increasing openness, reflection and an awareness of the complexity of aspects of teaching related to academic work across the disciplines, the communities can at the same time offer detailed knowledge about the genuine experiences of teachers with respect to teaching development, and about the preconditions for the supportive development.

The aim of the present study is to gain knowledge about the factors that support and constrain the development of teaching across the disciplines. University teacher, as participants of one learning community at the university, were the key informants. The features of the community will be elaborated in the next section. The overall aim of the study is to develop structures that support teachers in their continuous pedagogical development at the university level. Thus, the following research question was addressed: What factors do university teachers find to be supportive or constraining in the development of teaching?

\section{Methodology Context of the study}

The study was conducted within the context of a multidisciplinary network project at the University of Jyväskylä, which is one of the largest research universities in Finland. The university has seven faculties, approximately 2,500 employees and approximately 15,000 students. The origins of the university lie in the first Finnish-speaking teacher training college launched in 1863. The actual university, with several faculties, was established in 1966. It offers formalised university teacher training, short training courses and network project activities for its teaching staff.

The multidisciplinary network project annually calls for university teachers — who represent various disciplines, and who are also interested in developing the teaching of a focussed theme - to work together and support each other during a one-year project. The network aims to: 1) develop pedagogically high-quality learning possibilities for students, and to support their activities as learners; 2) support teachers in their continuous pedagogical developmental work; 3) facilitate pedagogically meaningful ways of using ICT for learning; 
and 4) produce evidence-based knowledge on the experiences of teachers and students during developmental interventions.

The main focus of teaching development is based on the strategy of the university, which is jointly shared among the teachers. A 'bottom-up' policy with respect to the teachers' expertise and autonomy, however, is a cornerstone of educational development in the network. In line with this strategy, the teachers themselves formulate the final aims and methods of the pedagogical development. They are supported in their work by peer supportoriented frequent network activities, dialogic and need-based mentoring, and evidence-based knowledge from the experiences of teachers and students during developmental interventions. The one-year length of the project is supposed to provide the teachers with enough time to make changes in their teaching practices. Following the completion of the project, teaching development is expected to continue further and to take root in every department.

The teachers, who are at different stages of their career paths, are invited to participate in the network in pairs or in groups (from three to six people per subject or programme). The participants are selected by the steering group of the network; selection is based on the applications, including the applicants' initial plans for their developmental work. The whole network is led by a vice head, with the support of a steering group. Attending this project that is supported by the head of the university offers status value for both the individuals and the units they represent in teaching development, as well as collective support for the shared developmental tasks.

The network project in many ways resembles a faculty learning community (FLC) as defined by Cox (2004). Like an FLC, the network is comprised of a cross-disciplinary teacher group that engages in a long-lasting, structured and collaborative programme that includes community building among teaching staff and frequent activities that promote learning. In addition, group dynamics (e.g., developing empathy, trust and appreciation) and constructive working methods that inspire and empower the participants are at the core of the activities.

\section{Participants and data collection}

The data were collected by interviewing 51 university teachers who had developed their teaching methods within the network during the years 2011-2014. The teachers represented all of the faculties of the university and a variety of disciplines, including the humanities, information technologies, social sciences, educational sciences, business, sport and health sciences, and natural sciences. This ensured that the largest possible variation, in terms of disciplines, was captured in the study. In this study, we use the term 'teacher' to refer to teaching staff whose main duties include research, teaching, and societal influencing; which of these three factors is emphasised varies, however, depending on the position.

The 26 semi-structured interviews of approximately 60 minutes each were conducted in the middle of each project period; they consisted of nine individual, twelve pair, and five group interviews. The interviews dealt with the following seven themes: 1) teaching development as a part of work, 2) the factors supporting the development of teaching in one's own work, 3) the prerequisites and barriers of the developmental work, 4) the attitude and support of the department head, 5) the teachers' needs for support, 6) the factors that supported continuous teaching development at the university level, and 7) the experiences of the support that the network offered.

\section{Analysis}

The transcribed data from the interviews were analysed in a data-driven and code-oriented manner using the procedures for qualitative thematic analysis (Braun and Clarke 2006). The analysis was carried out according to the following steps: 
1. Familiarisation with the data. The data were read in an active way by searching the contents for various meanings related to the research question, and by noting down initial ideas.

2. Generation of initial codes. The data were read intensively by coding and organising it into meaningful groups. In terms of themes among the participants, the length of an analysis unit varied from a single person's statements to short dialogues. The central idea of the initial coding was that the data were coded into as many potential groups as possible by trying to preserve various meanings. This meant that an extract could be coded as many times as was relevant. At this stage, the initial codes were labelled with a few words or shortened sentences.

3. Classification of relevant information. At the next stage, the different codes were sorted into potential themes by thinking about the relationships between codes and between themes.

\section{Results}

The factors that could be experienced as either supportive or constrained in the teaching development arose thematically in two ways; Table 1 summarises the main viewpoints of the results. Some grew from the authenticity of development (Table 1): as targets that were aspired to; as ways of both assessing the work and gaining knowledge about the success of the development; and as opportunities for constructing continuity for the developmental work. In other cases, the circumstances of the developmental work influenced the teachers and were manifested in: ways of supporting the development of teaching as a part of an academic work; the operational environment's concrete tools and support practices to promote pedagogical change; the support that came from the collegial networks, as well as from the management and leadership of the university. All of these items were seen as being important determinants (either supportive or constraining) that influenced the teachers' aspirations and motivations to develop. It should be noted that the detailed results, and the extracts of the interviews described in this section, represent the variety of the teachers' experiences, and not their frequency.

Table 1 near here

\section{Authenticity of the development}

The authenticity of the development was a meaningful factor for the teachers in the whole process. First, the authenticity was related to the definition of the development target, particularly the teachers' active and initiative role in that development. The teachers valued the bottom-up policy that was carried out in the development of teaching during the network, because they thought that the real needs and aims of the developmental work arose from one's own work. In order to change teaching practices, they thought that development should be integrated into the teachers' daily work and their own initiatives. In this way, the teachers can act as active agents and enhance the authentic development of teaching, and thus engage 
in that work. In one group interview, this kind of authentic base for the work was described as follows:

This way of promoting things and enhancing the development of teaching is quite good ... all teachers are doing what they had to do anyway; however, [now they are] trying to incorporate new ideas into their own work. Doing is the core of action. It's better than the alternative way of sitting everybody down and making [us] listen to a person from another discipline telling us how we should teach in our own field. It doesn't work.

While the teachers emphasised their own active roles as being necessary for development at the grassroots level, some teachers also felt that a broad theme of development in university education would need a more systematic definition of strategy at the university level; the teachers' involvement in that kind of defining would be essential as well. The specified strategy would help single teachers to choose between functional pedagogical models, and thus to see desirable ways for their own development of teaching. They thought the strategy should not be too pressing to the teachers, however, as expressed in the following statement:
More general and long-term defining work would be done together with the grassroots-level development. However, it is wishful thinking that that everyone would start to use the one and only model for their development. It is worth it that we gather various functional models from these offshoots and experiences ... but there has to be some kind of pearl of wisdom in the courses of action, that the ideas come from the teachers, and the strategy will not be too ordering.

Second, authenticity, as a supportive factor of the development, emerged in the ways in which the teachers could obtain evidence-based assessment knowledge about the development. The teachers viewed that the research supported their work, as it was designed with the aim of analysing the learning experiences of students and their study success in the developed studies, as well as the teachers' experiences about the development process. Although the final results of the analyses will be finished after the project is completed, the teachers highlighted that those research activities were essential to their future teaching development. Some of the teachers (for example educational scientists) perceived that this kind of pedagogical study constitutes a natural part of their own work, whereas others stressed the meaning that the project study offered them in the network. The latter group also thought the immediate observations and recommendations about the pedagogy that were made by the project researchers during the developmental process were useful, as were the preliminary results of the student questionnaire. As one teacher from the natural sciences described (below), the fact that the research was implemented by outsiders offered the teachers several views about development that were difficult to see from inside the teacher group; in exchange, they were free to concentrate on their own development goals.

The other ones study here; we don't need to try to do that. We get the knowledge, and this is positive and supportive... [as are] these observations, when the outside researchers make observations that the teachers couldn't make by themselves. And the [knowledge] doesn't come in the form of student feedback, which is often focussed on more practical questions. It is interesting to hear about these results of the research.

Although in general the teachers valued the evidence-based approach to teaching development, some were sensitive to the manner in which their courses would be assessed, and wondered whether these assessments offered essential information in terms of the aims of the course and its development. 
It's important that learning is assessed, but it's also essential to think in what stage and how the assessment will be implemented. I have taught the same course since the beginning of the 2000s. I have often wondered whether the students who completed my course did better in their university studies than those who didn't attend my course. My opinion is that my course offers versatile skills for the students, and that this type of assessment would be interesting: not so much gathering information about the immediate experiences from the students about the course.... I don't react to [such assessments], but simply the statistical analysis of the study success between the students who participated and those who didn't [would be interesting].

The third perspective on authenticity was manifested as the possibilities to construct continuity for developmental work with the help of: 1) iterating the developed ideas in one's own teaching, and 2) extending the developmental work into other courses. In some cases, the developmental projects that the teachers had decided to implement during the network period often constituted a continuum to the work that had been started before the network period; in other cases, the present initiatives started a completely new way of teaching. Thus, the teachers emphasised the need for understanding the development of teaching in a wider timeframe than what the network period offered them. The network period gave extra support and power to implement initiatives, but as the following interview extract reveals, the oneyear restriction on the time for the development even needled some teachers:

\section{It is very strange to perceive these tasks as projects. Continuous development presumes that the task will end in a natural way, not that it will have some kind of formal deadline.}

When the teaching development was implemented in the single courses, the teachers felt that the pedagogical interventions should extend to other courses, or even the whole programme. They analysed their developing work as a continuum and as a part of the broader development of curricular and pedagogical thinking as departments and units. From this view, opportunities for sharing ideas and extending the developmental work to other courses arose as important factors that support or constrain authentic and continuing development. One teacher described her aspiration as follows:

What I think and ask for:... instead of piloting [a] single course, I would ask more for discussion about the principles; what are our aspirations [for] development concerning [a] specific topic in the whole education? It is really important to me that ... you have a way to go ahead with your development and that you can bring about a change at the programme level.

The teachers saw the support that they received through participating in network activities at the university level (e.g., the results of the assessment study, and seminars for the dissemination of knowledge about the pedagogical development) as being helpful in extending the developmental work throughout the various departments. Convincing one's colleagues about the influence of the pedagogical development, however, was not always experienced as an easy task for the teachers. One teacher characterised the need for the help of outsiders by saying:

'No man is a prophet in his own land', and it is hard to make changes. Outside support makes it easier [at the department level].

In addition, the teachers viewed access to the network as rewarding in itself, by garnering attention as developers and thereby promoting their pedagogical topics in the university 
community. They emphasised the need for opening the network activities to all teachers at the university by sharing thoughts, ideas, and good practices about pedagogical implementations. According to the interviewees, many teachers at the university actively developed teaching methods and learning environments in their work, and the network itself represented a limited group. Some interviewees identified the 'foot soldiers' in their departments who had developed their teaching practices, but for various reasons saw few opportunities to gravitate to network activities.

\section{Circumstances of the development}

Based on the interviews, the teachers evoked various factors in their work circumstances that they experienced as being either supportive or constraining in the development of teaching, which they considered to be part of their academic work. Those teachers who could build their careers as researchers of higher education saw that the development of teaching and research was integrated in their work. They were typically educational scientists who perceived the pedagogical interventions as a natural part of the research process, as is evident in the following exchange:

Teacher 1: This is certainly pedagogical development, but research activities are closely included in this work; just in this autumn's course, the research data will be gathered, and the plan is to publish the results in some forum ...

Teacher 2: [continues the former's thought] ... in a way teaching and research constitute a strong union; they support each other. And in my situation, pedagogical development is possible only in those cases where it will enable our research activities.

The teachers who came from disciplines other than education and whose research interests were not related to higher educational phenomena experienced teaching development as showing a contradiction arising from the pressures of allocating time between teaching and research and the lack of an equal rewards system for these areas. This is seen in the exchange below:

Teacher 1: ... The development of teaching does not have a mandate in the university now.

Teacher 2: No, it does not.

Teacher 1: This is strongly related to [the emphasis on] research ... and to the point that you qualify yourself as a teacher by acting as a good researcher.

Teacher 2: A researcher, yes.

Teacher 1: ... I see [this] as a big structural question: that [if] we would have as legitimate a path [as researchers do] to ... proceed to the teaching-based tasks and also to get a higher salary ... and to get as valuable a position by developing teaching as by doing research. Now this is ... [an] indefinable thing when you want to be qualified for a university teaching vacancy.

The teachers had a uniform attitude to the development of teaching: they saw it as demanding and time-consuming, and that it seemed to question their own capacity, especially in cases where it aimed to change practices and renew pedagogy. For example, they viewed moving teaching development from traditional lecturing towards the use of ICT in education as requiring a notable allocation of time for planning and designing - invisible work that does not appear in the end product. Thus, the teachers viewed financial resources, offered to them 
by the network, as a precondition to whether or not this kind of development could take place. They perceived, however, that taking time for the development of teaching was challenging. To cite two teachers' statements, the time it took seemed to return to the question of the academic work as a whole, and to be an individually resolved question of which tasks were preferred:

You simply take time for the development of [your] teaching from somewhere!

or

It's not worth spending the time on [teaching development], because in the end you take time from research.

In addition, the teachers viewed the opportunities in the operational environment for obtaining pedagogical and/or technological support — and the appropriate space, equipment, tools, or applications for renewing pedagogy — as being meaningful in their developmental work. Especially in the ICT-based initiatives, the teachers emphasised in a specific way the need for developing the present operational environment by taking the specific nature of elearning into account. In general, the teachers hoped that the present activities of the university's ICT services, including technological support, would be developed further to answer the multifaceted needs of future learning with ICT. The interviewed teachers constituted a rather heterogeneous group in their aspirations, expectations, and demands concerning the planning of the ICT-supported learning environment. Some of the teacher felt that the equipment, tools, and applications needed for ICT-supported teaching were not available, which thus restricted the developmental work. Others, on the other hand, thought that the present operational environment offered good opportunities for using ICT in a pedagogically meaningful way. Some teachers felt that nothing hindered them from taking an active role in the development of ICT-supported learning environment and acquiring the appropriate tools. These teachers felt that the ICT services of the university did not offer the support they needed; in order to develop ICT-supported learning in a meaningful way in their disciplines, they felt compelled to act independently. A rather commonly shared view among the teachers, however, was the need for pedagogical-technological mentoring and education related to using ICT in their teaching, and for sharing their experiences with ICT-based teaching development.

The interviewed teachers felt that the network with other teachers was supportive, as long as it was based on voluntary participation and trust among the participants; this resulted in sharing knowledge, experiences, and/or expertise. The general attitude towards networking with other teachers from different disciplines was responsive and open. Peer support empowered the teachers to aspire to aims that they couldn't have accomplished alone, as one teacher described:

I have jumped into [the] unknown-I don't know if I could have made it without my colleagues.

Meetings with other teachers from various departments also provided concrete ideas of how to teach in different ways:

When I heard about the other teachers' experiences of the demonstrations in their courses, it opened my eyes that it is also possible to teach in that way... It was a good surprise to me.... I started to wonder if it could work in my own teaching, too.

The supportive work with other teachers was manifested in a wide range, varying from the voluntarily based collaborative co-teaching with colleagues to forums that offered the 
possibility of having discussions with teachers from different disciplines. In the case of coteaching, jointly shared views and trust in each other appeared to be important supportive factors in teaching development. The following two interview extracts show how some teachers took considerable steps in networking with other teachers in co-teaching situations by estimating the possible quality of the relationship, and its meaning for future work together.

Teacher 1: I knew that [this] teacher was the one I would dare to start towards [the] unknown with.

Teacher 2: We are on the same wavelength ... [as far as] humour and views on development ... that we will not end up [on a] collision course.

The interviews also revealed, however, a few critical attitudes towards networking with other teachers who had an interest in the development of teaching. Some teachers emphasised that networking with other teachers must be considered and assessed carefully, by asking whether the collaboration increased the effectiveness of the work, especially when measured as research outcomes (e.g., publications). Otherwise, they perceived the meaning of the network to be inconsequential for teaching development. In addition, in certain co-teaching cases, the lack of desire for common development due to differences in views - and thus bad relations between colleagues - seemed to constrain purposeful development. The following extract exposes the situation from the perspective of two teachers from the larger co-teaching group.

Teacher 1: We have differences of views between us and this teacher. He has constituted his own view based on his own experience, and what irritates us now is that he has stuck to his own experiences.

Teacher 2: And also the starting point to the development is wrong ... that what is viewed ... obviously, the most important thing in this community is the kind of need to be right from the teacher's point of view ... that I am wise, and I already knew this beforehand.

Teacher 1: Somehow I see that we should be able to change the climate somehow, that the first thought wouldn't be that are you spying on me. Instead, there would be genuine desire ...

Teacher 2: [continues the former's thought] ... to develop teaching.

The teachers mentioned the support of the university head on all levels as being important to the development of teaching. They experienced the encouragement and interest of the head as worthwhile; this also somehow legitimised the task of development. The interviewed teachers, however, held various attitudes towards the department head about their developmental work of teaching. Some teachers characterised the general attitude of the head to developmental work as positive; they received unreserved support and attention. Others, however, felt that the head didn't support their developmental teaching work, and expressed an undervaluing attitude to the development of teaching, as in the following exchange:

Teacher 1: In our department, the attitude to development of all teaching is quite negative.

Interviewer: How does it appear?

Teacher 2: Well, the development of teaching is not valued at all. It's like ... saying that it is fine that you develop, but how about you ... do research [instead]? 


\section{Concluding discussion}

This study has aimed to identify the factors that university teachers perceive as supportive or constraining in teaching development. The study was implemented in the special context of a network project, which is not a widely established form of developmental support for teachers compared to more general formalised training programmes and short training courses. In this context, educational development is considered as simultaneous questions about developing teachers as individuals, strategic questions about the shared aim of aspiring at the university level, and communal questions about affecting change in departmental cultures. It is clear that the results to some extent reflect these contextual factors. However, when we think about the responses to the expectations for the renewal of learning environments and cultures in higher education, it is inevitable that educational development is moving towards collectively constructed (and negotiated) strategic forms (Cox 2004; Trowler and Bamber 2005). The results of this study are thus also useful at a more general level.

The results reveal that the supportive factors in teaching development arise from the nature of the development itself, which provides the participants with opportunities to act as active agents in an authentic process of development, gaining assessment knowledge concerning the development and constructing continuity in the developmental work. From the viewpoint of authenticity, we regard the following practical questions as important for the further development and planning of interventions that engage teachers in communal educational development: What are the cross-disciplinary pedagogical challenges to development at the university level? How will developmental work around these issues be integrated in teachers' daily work? What are teachers' opportunities for getting involved in the definition of developmental goals and methods? How can assessment of development be integrated as a part of the various developmental processes? How can needs-based support be acquired? How can teachers' pedagogical research in different disciplines best be supported? How can teachers construct continuity in developmental work?

Based on the interviews with the teachers, the circumstances of the developmental work can also be seen to have an essential supportive or constraining role in teaching development. At its best, a supporting environment would be one where the development of teaching in the university context is recognised as being valuable and rewarding, and where it is also encouraged by the management. In the teachers' daily work, such support was manifested in the ability to allocate time to development, opportunities in the operational environment, and the possibility to construct an eligible career path as a teacher-rather than just as a researcher. This is related to the general discussion about the value and recognition of teaching and its development (Alpay and Verschoor 2014), as well as to the tension between research and teaching in universities (Lai, Du, and Li 2014; Taylor 2007). This tension often reflects the political priorities inherent in universities. Alpay and Verschoor (2014) indicated that the perceived value of teaching recognition remains overshadowed by research accomplishments, although recognition and support for teaching development have the potential to promote a stronger teaching culture. In our study, we found that many teachers had to struggle with time allocation, and to work under a pressure whether to develop teaching or doing research in their field. This appears as a central problem in several disciplines. Thus, we see that financial policy of higher education could be more supportive for the enhancement of teaching. Moreover, measurement tools for evaluating quality of teaching is needed. Teaching Excellence Framework (TEF) (Times Higher Education 2015) introduced in the UK is a promising example of a government supported national endeavour to raise status of university teaching. Our study is in line with earlier research indicating the important role of institutional support and supportive leadership in managing teachers' 
workloads and in contributing to their motivation (Ramsden 2003; Winter and Sarros 2002). In addition, offering rewards to teachers has been proven to be central to developmental success (Alpay and Verschoor 2014; Ramsden 2003; Stigmar 2008; Winter and Sarros 2002).

In addition, the role of research focusing on teaching development is important, providing evidence-based knowledge to teachers on what is going well and what needs to be developed further. In the current study, the teachers from various disciplines emphasised the importance of the project study that the network offered them but perceived their own interest and capacities in conducting pedagogical research to be minimal. This recalls similar findings about university teachers' unwillingness to be involved in the scholarship of teaching (Havnes and Stensaker 2006). Based on our study, we suggest developing further the model based on collaborative scholarship between developing teachers and higher education researchers in order to improve both evidence-based teaching practices and research capacity in the field of pedagogy in various disciplines.

Earlier studies have recognised the value of social support and the sharing of good practices (Alpay and Verschoor 2014; Stigmar 2008). Based on our findings, one of the next steps is to support in a more integrated manner the development initiatives among different groups, departments and faculties. Support and expertise in learning technologies at the level of the network initiative could boost this. One of our guidelines is also that the outcomes should be shared locally and that bridges should be built between universities in developing teaching.

An essential issue is the continuation of developmental activities. Supported projects for teaching development are usually for one year, although in general they continue independently. We have found that at least one-and-a-half years are needed to realise changes in the developed courses. It would also be beneficial to have longer periods for the intensive support of each project. This would offer more opportunities for a progressive cyclic design and development (Reeves, Herrington, and Oliver 2005) and the sharing of good practices. In addition, earlier studies have indicated that teaching development is a time-consuming process that requires long-term support and enthusiasm rather than a demand for immediate results (Stigmar 2008; Trowler and Bamber 2005). Despite less than ideal conditions, many academics learn to teach excellently. Enthusiasm and a commitment to improving university teaching (e.g., listening to students about how to help them learn) are crucial in making changes happen.

We can conclude that the success of teaching development is dependent on multiple intertwining epistemological, pedagogical and social factors as well as the technological infrastructure and support structure of the whole university. There is no single solution for improving the quality of university teaching. Our study reveals a need to find a balance between bottom-up policies emphasising the active agency of teachers and university-level ('top-down') approaches based on a strategic vision for teaching development. Our findings suggest that both individual initiatives and wholesale changes (operating at several levels of the system; Ramsden 2003) are needed. Although it must be emphasised that this study focuses on only one university, we suggest that interactions and negotiations between the institutional levels are likely to make educational development successful. Due to the changes in our knowledge-based society and its demands that we renew university teaching, further studies are needed to understand the prerequisites for developing innovative learning environments, particularly those that incorporate the rich utilisation of ICT for pedagogically meaningful purposes. This is important so that universities can make research-based decisions and develop their own learning environments and structures in a flexible and agile way. 


\section{References}

Adams, Di. 2000. "Views of academic work." Teacher Development: An international journal of teachers' professional development 4 (1): 65-78. doi:

10.1080/13664530000200097.

Alpay, Esat, and Rianne Verschoor. 2014. "The teaching researcher: faculty attitudes towards the teaching and research roles." European Journal of Engineering Education 39 (4): 365376. doi:10.1080/03043797.2014.895702.

Bamber, Veronica. 2008. "Evaluating lecturer development programmes: Received wisdom or self-knowledge." International Journal for Academic Development 13 (2): 107-116. doi: 10.1080/13601440802076541.

Bamber, Veronica, Lorraine Walsh, Charles Juwah, and David Ross. "New lecturer development programmes: A case study of Scottish higher education institutions." Teacher Development 10 (2): 207-231. doi:10.1080/13664530600773069.

Bransford, John, Reed Stevens, Dan Schwartz, Andy Meltzoff, Roy Pea, Jeremy Roschelle, Nancy Vye, Pat Kuhl, Philip Bell, Brigid Barron, Byron Reeves, and Nora Sabelli. 2006. "Learning theories and education: Toward a decade of synergy." In Handbook of educational psychology, edited by Patricia A. Alexander and Philip. H. Winne, 209-244, Mahwah, NJ: Erlbaum (American Psychological Association).

Braun, Virginia, and Victoria Clarke. 2006. "Using thematic analysis in psychology." Qualitative Research in Psychology 3 (2): 77-101. doi:10.1191/1478088706qp063oa.

Christopher, Justice, James Rice, Wayne Warry, Sue Inglis, Stefania Miller, and Sheila Sammon. 2007. "Inquiry in higher education: Reflections and directions on course design and teaching methods." Innovative Higher Education 31 (4): 201-214. doi:10.1007/s10755-0069021-9.

Cox, Milton. D. 2004. "Introduction to faculty learning communities." New Directions for Teaching and Learning 97:5-23. doi:10.1002/tl.129.

Crouch, Catherine H., and Eric Mazur. 2001. "Peer instruction: Ten years of experience and results.” American Journal of Physics 69, 970-977. doi:10.1119/1.1374249.

Eteläpelto, Anneli, Katja Vähäsantanen, Päivi Hökkä, and Susanna Paloniemi. 2014. "Identity and agency in professional learning." In International handbook of research in professional and practice-based learning, edited by Stephen Billet, Christian Harteis, and Hans Gruber, 645-672, Dordrecht: Springer.

Fanghanel, Joëlle. 2004. "Capturing dissonance in university teacher education environments." Studies in Higher Education 29 (5): 575-590.

doi:10.1080/0307507042000261553. 
Gibbs, Graham, and Martin Coffey. 2004. "The impact of training of university teachers on their teaching skills, their approach to teaching and the approach to learning of their students." Active learning in higher education 5 (1): 87-100.

doi:10.1177/1469787404040463.

Glenn, Diana, Fay Patel, Salah Kutieleh, Jane Robbins, Heather Smigiel, and Alan Wilson. 2012. "Perceptions of optimal conditions for teaching and learning: A case study from Flinders University." Higher Education Research \& Development 31 (2): 201-215. doi:10.1080/07294360.2011.555390.

Gosling, David. 2001. "Educational development units in the UK - what are they doing five years on?" International Journal for Academic Development 6 (1): 74-90.

doi:10.1080/13601440110043039.

Gosling, David. 2009. "Educational development in the UK: A complex and contradictory reality." International Journal for Academic Development 14 (1): 5-18.

doi:10.1080/13601440802659122.

Havnes, Anton, and Bjørn Stensaker. 2006. "Educational development centres: From educational to organizational development?" Quality assurance in Education 14 (1): 7-20. doi:10.1108/09684880610643584.

Hodkinson, Phil. 2005. "Reconceptualising the relations between college-based and workplace learning." Journal of Workplace Learning 17 (8):521-532.

doi:10.1108/13665620510625381.

Häkkinen, Päivi and Raija Hämäläinen. 2012. "Shared and Personal Learning Spaces: Challenges for Pedagogical Design.” Internet and Higher Education 15 (4): 231-236. doi:10.1016/j.iheduc.2011.09.00.

Hökkä, Päivi, and Anneli Eteläpelto. 2014. "Seeking new perspectives on the development of teacher education: A study of the Finnish context." Journal of Teacher Education 65 (1): 3952. doi:10.1177/0022487113504220.

Jääskelä, Päivikki, Anna-Maija Poikkeus, Kati Vasalampi, Ulla Maija Valleala, and Helena Rasku-Puttonen. 2016. "Assessing agency of university students: Validation of the AUS Scale.” Studies in Higher Education. doi:10.1080/03075079.2015.1130693.

Jääskelä, Päivikki, and Pia Nissilä. 2015. "Identifying themes for research-based development of pedagogy and guidance in higher education." Scandinavian Journal of Educational Research 59 (1): 24-41. doi:10.1080/00313831.2013.838696.

Kirkwood, Adrian, and Linda Price. 2014. "Technology-enhanced learning and teaching in higher education: what is 'enhanced' and how do we know? A critical literature review." Learning, Media and Technology 39 (1): 3-36. doi:10.1080/17439884.2013.770404.

Lai, Manhong, Ping Du, and Linlin Li. 2014. "Struggling to handle teaching and research: a study on academic work at select universities in the Chinese Mainland." Teaching in Higher Education 19 (8): 966-979. doi:10.1080/13562517.2014.945161. 
Lave Jean, and Etienne Wenger. 1991. Situated Learning. Legitimate peripheral participation. Cambridge: University of Cambridge Press.

Lee, Alison, Catherine Manathunga, and Peter Kandlbinder. 2010. "Shaping a culture: Oral histories of academic development in Australian universities." Higher Education Research \& Development 29 (3): 307-318. doi:10.1080/07294360903252128.

Postareff, Liisa, Sari Lindblom-Ylänne, and Anne Nevgi. 2007. "The effect of pedagogical training on teaching in higher education." Teaching and Teacher Education 23 (5): 557-571. doi:10.1016/j.tate.2006.11.013.

Ramsden, Paul. 2003. Learning to teach in Higher Education. Second edition. London: Routledge.

Prebble, Tom, Helen Hargraves, Linda Leach, Kogi Naidoo, Gordon Suddaby, and Nick Zepke. 2004. "Impact of student support services and academic development programmes on student outcomes in undergraduate tertiary study: A synthesis of the research." Wellington: Ministry of Education. Accessed 10 October 2016. http://www.educationcounts.govt.nz/_data/assets/pdf_file/0013/7321/ugradstudentoutcomes. pdf

Reeves, Thomas C., Jan Herrington, and Ron Oliver. 2005. "Design research: a socially responsible approach to instructional technology research in higher education." Journal of Computing in Higher Education 16 (2): 97-116. doi:10.1007/BF02961476.

Roxå, Torgny, and Katarina Mårtensson. 2008. "Strategic educational development: A national Swedish initiative to support change in higher education." Higher Education Research \& Development 27 (2): 155-168. doi:10.1080/07294360701805291.

Stenfors-Hayes, Terese, Maria Weurlander, Lars O. Dahlgren, and Håkan Hult. 2011. "Medical teachers' professional development-perceived barriers and opportunities." Teaching in Higher Education 15 (4): 339-408. doi:10.1080/13562517.2010.493352.

Stes Ann, Liesje Coertjens, and Peter Van Petegem. 2010. "Instructional development in higher education: Impact on teachers' teaching behaviour as perceived by students." Instructional Science 41 (6): 1103-1126. doi:10.1007/s11251-013-9267-4.

Stigmar, Martin. 2008. "Faculty development through an educational action programme." Higher Education Research \& Development 27 (2): 107-120. doi:10.1080/07294360701805242.

Su, Yi-Hsuan. 2011. "The constitution of agency in developing lifelong learning ability: The 'being mode'." Higher Education 62 (4): 399-412. doi:10.1007/s10734-010-9395-6.

Taylor, John. 2007. "The teaching: research nexus: A model for institutional management." Higher Education 54 (6): 867-884. doi:10.1007/s10734-006-9029-1.

Times Higher Education. 2015. "Teaching excellence framework (TEF)." Accessed November 14 2016. https://www.timeshighereducation.com/news/teaching-excellenceframework-tef-everything-you-need-to-know 
Trede, Franziska, Rob Macklin, and Donna Bridges. 2012. "Professional identity development: A review of the higher education literature." Studies in Higher Education 37 (3): 365-384. doi:10.1080/03075079.2010.521237.

Trigwell, Keith, and Michael Prosser. 1996. "Changing approaches to teaching: A relational perspective." Studies in Higher Education 21 (3): 275-284. doi:10.1080/03075079612331381211.

Trowler, Paul, and Roni Bamber. 2005. "Compulsory higher education teacher training: Joined-up policies, institutional architectures and enhancement cultures." International Journal for Academic Development 10 (2): 79-93. doi:10.1080/13601440500281708.

Vanhanen, Hannu, Kaisu Pitkälä, Pauli Puolakkainen, Timo E. Strandberg, and Kirsti Lonka. 2001. "The problem-based learning tutorial laboratory — a method for training medical teachers." Medical teacher 23 (1): 99-101. doi:10.1080/0142159002005695.

Warhurst, Russell, P. 2006. "'we really felt part of something': Participatory learning among peers within a university teaching-development community of practice." International Journal for Academic Development 11 (2): 111-122. doi:10.1080/13601440600924462.

Warhurst, Russell P. 2008. "'Cigars on the flight-deck': New lecturers'participatory learning within workplace communities of practice." Studies in Higher Education 33 (4): 453-467. doi:10.1080/03075070802211828.

Winter, Richard, and James Sarros. 2002. "The academic work environment in Australian universities: a motivating place to work?" Higher Education Research \& Development 21 (3): 241-258. doi:10.1080/0729436022000020751. 
Table 1. Supportive and constraining factors in the development of teaching

\begin{tabular}{|c|c|c|c|}
\hline \multicolumn{2}{|r|}{ FACTOR } & Supports when: & Constrains when: \\
\hline \multirow{3}{*}{ 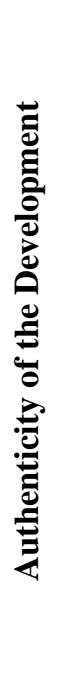 } & $\begin{array}{l}\text { Definition of } \\
\text { development } \\
\text { target }\end{array}$ & $\begin{array}{l}\text { - It is integrated into the teachers' } \\
\text { everyday work } \\
\text { - Supports the teachers' active agency }\end{array}$ & $\begin{array}{l}\text { - Is perceived as coming from 'top } \\
\text { down' orders, without the } \\
\text { teachers' involvement }\end{array}$ \\
\hline & $\begin{array}{l}\text { Assessment of } \\
\text { the } \\
\text { development }\end{array}$ & $\begin{array}{l}\text { - Research activities are integrated into } \\
\text { the development } \\
\text { - Assessment knowledge is available } \\
\text { during the process of development } \\
\text { - It offers both practical guidance and } \\
\text { evidence-based knowledge }\end{array}$ & $\begin{array}{l}\text { - The manner of the assessment } \\
\text { does not support the aims of the } \\
\text { development }\end{array}$ \\
\hline & $\begin{array}{c}\text { Continuity of } \\
\text { the } \\
\text { developmental } \\
\text { work }\end{array}$ & $\begin{array}{l}\text { - Opportunities for iteration and } \\
\text { extension of the developmental work } \\
\text { exist } \\
\text { - Forums for the dissemination of } \\
\text { knowledge about the development are } \\
\text { organised at the university level }\end{array}$ & $\begin{array}{l}\text { - Development is seen in a limited } \\
\text { time perspective } \\
\text { - Extension of the development } \\
\text { doesn't draw response from the } \\
\text { teaching staff }\end{array}$ \\
\hline \multirow{4}{*}{ 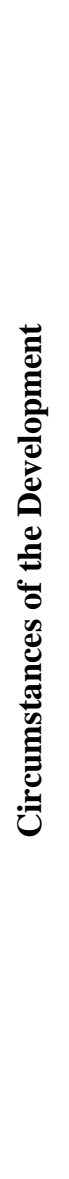 } & $\begin{array}{c}\text { Teaching } \\
\text { development } \\
\text { as a part of } \\
\text { academic work }\end{array}$ & $\begin{array}{l}\text { - Higher education research and subject } \\
\text { teaching are integrated with each other } \\
\text { in one's own work } \\
\text { - Enough time has been allocated in } \\
\text { relation to the aim of the development, } \\
\text { either to improve the present } \\
\text { implementation or to create new } \\
\text { implementations }\end{array}$ & $\begin{array}{l}\text { - A financial and reward system at } \\
\text { the university supports research, } \\
\text { but not teaching } \\
\text { - Time has not been allocated at } \\
\text { all, or allocated unrealistically for } \\
\text { development }\end{array}$ \\
\hline & $\begin{array}{c}\text { Operational } \\
\text { environment }\end{array}$ & $\begin{array}{l}\text { - Paedagogical and/or technological } \\
\text { support is available to the teacher } \\
\text { - Up-to-date equipment and tools are } \\
\text { available, both to teachers and students }\end{array}$ & $\begin{array}{l}\text { - It does not take the specific nature } \\
\text { of the development into account } \\
\text { - Offers limited options for using } \\
\text { equipment and tools, and getting } \\
\text { support for the choices made by } \\
\text { the teacher }\end{array}$ \\
\hline & $\begin{array}{l}\text { Network and } \\
\text { collaboration } \\
\text { with other } \\
\text { teachers }\end{array}$ & $\begin{array}{l}\text { - Is voluntary for participators } \\
\text { - Is based on trust, allowing multiple } \\
\text { views from various disciplines (network) } \\
\text { - Is based on shared views (co-teaching) } \\
\text { - Produces utility in terms of sharing } \\
\text { knowledge, experiences, and/or } \\
\text { expertise }\end{array}$ & $\begin{array}{l}\text { - Its aims or courses of action are } \\
\text { perceived as non-effective in } \\
\text { terms of the development } \\
\text { - The desire for common } \\
\text { development is lacking }\end{array}$ \\
\hline & $\begin{array}{c}\text { Management } \\
\text { and leadership }\end{array}$ & $\begin{array}{l}\text { - Legitimises, and gives 'permission' to } \\
\text { develop teaching } \\
\text { - Is actively engaged in development by } \\
\text { encouraging, supporting, and showing } \\
\text { interest in the teachers' work }\end{array}$ & $\begin{array}{l}\text { - Undervalues the development of } \\
\text { teaching among other teacher } \\
\text { tasks (e.g., research, publication) }\end{array}$ \\
\hline
\end{tabular}

